\title{
CUSTO DE PRODUÇÃO E RENTABILIDADE PARA CULTURA DA SOJA NAS VARIEDADES CONVENCIONAL E TRANSGÊNICA EM MATO GROSSO
}

\author{
Nataliê Cristhy Guzatti ${ }^{1}$ \\ Cleiton Franco ${ }^{2}$
}

\section{RESUMO}

O estado do Mato Grosso, se destaca como maior produtor de soja do país, diante disto o objetivo deste trabalho foi determinar e comparar os custos de produção e rentabilidade para a cultura da soja, entre as variedades transgênica e convencional no estado do Mato Grosso, através de levantamento de dados coletados para as safras 2008/09, 2009/10, 2010/11, 2011/12, 2012/13, 2013/14, sobre os custos de produção. A metodologia utilizada baseou-se na coleta de dados por meio de procedimento painel utilizada pelo Instituto Mato-grossense de Economia Agropecuária (IMEA) com produtores rurais do estado de Mato Grosso. Confirmaram-se desvantagens em relação à ordem dos custos para a variedade transgênica, pois os resultados obtidos admitiram a variabilidade nos preços dos insumos (custos variáveis) e também dos preços de comercialização praticados nas distintas regiões. Visto que a análise demonstrou que os produtores que adotaram a variedade da tecnologia transgênica obtiveram custos superiores com químicos e sementes quando comparado aos custos da variedade convencional. E na outra via, a rentabilidade mostrou-se superior para a variedade convencional, devido aos menores custos de produção.

Palavras-chave: Custo de produção; rentabilidade; Soja Transgênica; Soja Convencional; Mato Grosso.

\section{INTRODUÇÃO}

Nas três décadas que se sucederam desde o início da sua produção de soja, Mato Grosso avançou no campo da tecnologia e produtividade, graças à inserção de avançado maquinário agrícola e biotecnologia usada na produção de grãos, pesquisa e descoberta de novas variedades, conquistando os mercados asiáticos, internacionalizando o produto primário e levando a produção agrícola ao patamar de destaque na balança comercial mato-grossense e brasileira (APROSOJA, 2010).

Em levantamento feito pelo Instituto Mato-grossense de Economia Agropecuária (IMEA), ficou demonstrado que a área de soja explorada por grandes grupos praticamente

\footnotetext{
${ }^{1}$ Acadêmica do curso de Ciências Contábeis da UNEMAT - Campus Tangará da Serra - MT, e-mail natalie_guzatti@hotmail.com;

${ }^{2}$ Professor do departamento do curso de Ciências Contábeis da UNEMAT - Campus Tangará da Serra - MT, email: franco.cleiton@gmail.com; 
dobrou em Mato Grosso nos últimos cinco anos, mostrando que os 20 maiores grupos plantaram 1,228 milhão de hectares na safra 2009/2010 e respondem por $20 \%$ dos 6,217 milhões de hectares cultivados com a oleaginosa no estado (APROSOJA, 2010; IMEA, 2010).

A literatura relacionada à contabilidade quanto ao propósito da utilização da análise de custeio variável associada à análise da rentabilidade e custos de produção proporciona adequada tomada de decisão quanto à mensuração dos diferentes custos de se produzir e o efeito das margens de receitas nos lucros em empresas agropecuárias (MALAVAZI, FUGITA E ROSA, 2006; ANDRADE ET AL, 2012). Na pecuária, também se utiliza tal metodologia de forma comparativa dos métodos de custeio por absorção e variável na análise de viabilidade de produção (EYERKAUFER, COSTA E FARIA, 2007; CELESTINO E SILVEIRA, 2009).

Já na discussão sobre soja convencional e soja transgênica que abarcam o embasamento econômico, foi considerada a análise dos custos de produção. Menegatti e Barros (2007) observaram em seu estudo comparativo de custos de produção de soja convencional e transgênica para Mato Grosso do Sul o comportamento inferior dos gastos com herbicidas da soja transgênica em relação à soja convencional. Além disso, apresenta menor custo por hectare de mão de obra. Bragagnolo et al (2007) analisaram os custos de produção da soja convencional e transgênica para o Paraná, resultando em menor custo para soja transgênica.

Esperancini et al (2007) em estudo realizado a respeito de retorno econômico incorporando análise de riscos, concluíram que a soja transgênica apresenta maiores retornos econômicos e menores riscos nas condições de preço. Posteriormente, em Mato Grosso, considerando custos de produção e inserção de análise de rentabilidade, Franco et al (2010) analisaram por meio de estudo de caso, com dados da Fazenda Missioneira na região de Campo Novo dos Parecis/MT, observando que os custos, especificamente os insumos, da soja transgênica são comparativamente menores aos da soja convencional.

O presente trabalho justifica-se por adotar uma metodologia comparativa ao diferenciar os custos de produção e rentabilidade de cinco regiões distintas em termos de preços de comercialização e custos de produção (dos insumos, mão de obra, impostos e taxas e transporte), considerando também seis períodos distintos, 2008 a 2013, para Mato Grosso. 
O objetivo deste trabalho é determinar comparativamente os custos de produção e rentabilidade para a cultura da soja, entre as variedades transgênica e convencional no Mato Grosso, através de levantamento de dados com metodologia painel, coletados para as safras 2008/09, 2009/10, 2010/11, 2011/12, 2012/13, 2013/14, verificando as disparidades nos custos de produção.

O presente trabalho oferece uma contribuição ao estudo de custos de produção, tendo como objetivos específicos: a) Levantar dados da soja convencional e transgênica sobre os gastos incorridos e a tecnologia utilizada na produção nas safras 2008/09, 2009/10, 2010/11, 2011/12, 2012/13, 2013/14; b) Analisar a rentabilidade baseada em custos de produção e preços de comercialização nas regiões identificadas.

\section{REFERENCIAL TEÓRICO}

\subsection{Soja Convencional x Soja Transgênica}

O sistema de plantio denominado soja convencional se caracteriza pelo uso de herbicidas seletivos à cultura da soja, havendo a necessidade de duas a três aplicações por safra, para o controle das ervas daninhas (FURLANETO et al, 2008 p.2).

Medeiros (2003) descreve que:

Visando à nutrição da planta, o método convencional faz uso de adubos químicos altamente solúveis, utiliza produtos químicos para o controle de pragas e doenças, como inseticidas, fungicidas e nematicidas, utiliza herbicidas para o controle de ervas daninhas. O sistema convencional apresenta a possibilidade de contaminação das águas por agroquímicos e não exige certificação.

Já o sistema de cultivo da soja transgênica, ou soja Round-up Ready $(R R)$ refere-se a linhagem geneticamente modificada da soja, criada e produzida pela empresa/indústria multinacional de agricultura e biotecnologia Monsanto, cuja é detentora da patente tecnológica. Ela é bastante similar ao cultivo convencional, diferenciado por alterações no manejo de produção e pela utilização de sementes geneticamente modificadas, através de um gene de outro organismo (bactéria) que possui resistência ao herbicida glifosato contido no produto Round-Up Ready também da multinacional, que combatem ervas daninhas. Pelo fato de ser resistente a esse produto, a plantação quando pulverizada com o glifosato não apresentam reações, somente as plantas que não são tolerantes a este principio ativo morrerão. (MEDEIROS, 2003; GREENPEACE, 2004).

Segundo Costa e Almeida (2007, p. 3): 
Fontes de pesquisa descobriram há pouco tempo uma nova ferramenta para produtores de grãos. Trata-se de uma modificação genética que possibilitou realizar e propor novos desafios a produtores agrícolas. A soja transgênica ou Roundup Ready (RR) como ficou conhecida, foi fruto de pesquisa e permitiu introduzir um gene resistente ao glifosato, produto utilizado para combater pragas e garantir melhor rendimento na hora da colheita.

A semente de soja transgênica foi desenvolvida na década de 1980, com a intenção de facilitar os tratos culturais da lavoura e proporcionar aumento de rentabilidade para os produtores, devido a redução de necessidade de pulverizações para controles de pragas. Além disto, o estudo vinculado mostra aumento da produtividade e a redução no teor de impureza e umidade nos grãos colhidos. (MENEGATTI, 2006).

O processo produtivo da soja vem sofrendo alterações e sendo aprimorada, visando melhoria na sua produtividade. Com o avanço das tecnologias, permite-se realizar novas descobertas. Segundo Costa e Almeida (2007) mesmo sendo incessante a busca pela eficiência na cadeia produtiva e cujo objetivo principal é alcançar lucratividade e redução de custos, vale ressaltar que pesquisas e experimentos também são feitos para a segurança dos consumidores.

A primeira referência à soja como alimento data de mais de 5.000 anos atrás. "O grão foi citado e descrito pelo imperador chinês Shen-nung, considerado o "pai" da agricultura chinesa, iniciando o cultivo de grãos como alternativa ao abate de animais. $\mathrm{O}$ grão, desde 200 anos (a.C.) já era a matéria prima essencial na nutrição dos chineses, na produção do tofu (leite de soja coalhado). Sem contar, que era utilizada como moeda, visto seu valor de venda e de troca por outras mercadorias. A soja de antigamente difere da atual: se desenvolviam perto dos rios e eram plantas rasteiras - conhecidas como soja silvestre. O processo de melhoramento e aprimoramento dessa cultura começou a ocorrer no século XI a.C., pelos cientistas chineses através de cruzamentos naturais (APROSOJA, 2013).

\subsection{Métodos de Custeio}

Conforme afirma Nascimento (2001, p. 53), custo é o somatório dos bens e serviços consumidos ou utilizados na produção de novos bens ou serviços, traduzidos em unidades monetárias. Nessa mesma linha de pensamento, Coronado (2006, p. 34) define a contabilidade de custos como sendo "uma ferramenta valiosa para mensuração e avaliação dos custos. Quando utilizada no ambiente interno, visa demonstrar os custos sobre os produtos, clientes, serviços, projetos, atividades, processos e outros dados de interesse dos gestores". Saber sobre 
a alocação dos custos permite criar alternativas e ferramentas para sanar possíveis lacunas e assim aumentar a rentabilidade e cultivar uma gestão eficaz.

Megliorini (2011) afirma que a contabilidade de custos é uma ferramenta auxiliar que permite que sejam atingidos os objetivos relacionados á obtenção do lucro, tomada de decisões, ao controle das operações, além de fornecer indicadores como: a) Apuração dos custos de insumos aplicados na produção; b) acompanhamento das operações e das atividades; c) controle para de redução dos custos de insumos aplicados; d) levantamento dos custos da empresa; e) conscientização na redução de desperdício de material e tempo ocioso; f) serve de base para tomada de decisões e resoluções de problemas; g) facilitação na preparação de orçamentos; h) margem de contribuição de cada produto; i) viabilidade do negócio; j) determinação de preço de venda da produção, dentre outros.

A valoração das operações, atividades ou produtos é mensurada através dos métodos de custeio. Existem vários e distintos métodos, que devem ser adotados de acordo com o objetivo e a necessidade de cada empresa. Se ela deseja reconhecer a margem de contribuição, deverá empregar o método de custeio variável, caso queira atender aos usuários externos o método indicado será o custeio por absorção, se o objetivo for o controle dos custos, identificando os desperdícios e as atividades desnecessárias o método a se utilizar será o custeio ABC. Por isso em algumas situações pode ser necessário a utilização de mais de um método simultaneamente. (MEGLIORINI, 2011; RIBEIRO, 2009).

\subsubsection{Custeio por Absorção:}

De acordo com Bruni e Famá (2004, p. 35) "os sistemas de custeio referem-se às formas como os custos são registrados e transferidos internamente dentro da entidade". Na utilização deste método de custeio ocorrerá a apropriação de todos os custos aos produtos, tanto os fixos quanto os variáveis que ocorrerão no período. O primeiro passo é separar os gastos em despesas, custos e investimentos. As despesas são alocadas na demonstração do resultado do exercício, os custos são separados em diretos e indiretos e alocados aos produtos (os custos diretos são apropriados aos produtos conforme as medições de consumo, e através de rateios alocam-se os custos indiretos) e os investimentos são ativados. (MEGLIORINI, 2011; GUERREIRO, 2011).

\subsubsection{Custeio Variável:}


O método que faz a alocação dos custos variáveis de produção na quantidade de produtos produzidos no período é denominado custeio variável. Na utilização deste mesmo método os custos fixos, que não fazem parte do custo do produto são reconhecidos como gastos do período assim como as despesas comerciais, administrativas e financeiras (GUEREIRO, 2011).

Crepaldi (2006, p. 117) ainda corrobora descrevendo que:

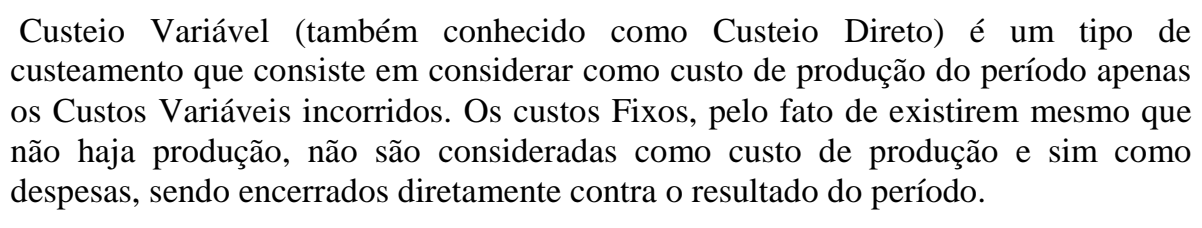

Ribeiro (2009, p.57) ao enfocar sobre a questão contábil afirma que "por contemplar apenas parte dos custos incorridos na fabricação, esse sistema não é aceito pelo Fisco para direcionar a contabilização dos custos incorridos ao produto". Visto que a soma dos custos indiretos juntamente com as despesas onera o resultado do período, tornando-se viável apenas para fins gerenciais a utilização deste método (GUERREIRO, 2011; MEGLIORINI, 2011; RIBEIRO, 2009).

Já de acordo com Martins (2001, p.249), "num mercado concorrencial é muito comum o contrário: a partir do preço de mercado chega-se ao target cost, ou seja, ao "custo-meta", que representa o máximo de custo e despesas a se incorrer para que o produto seja rentável." O custo representa o custo máximo suportável de forma a atingir o retorno desejável. É uma ferramenta, na visão de Martins (2001), na qual as empresas que não podem alterar sua política de preço por modificação na sua estrutura de custos, ou seja, o preço passa a ser praticado em função da oferta e da procura.

\section{METODOLOGIA}

Foram levantadas as bases de dados de custo de produção de cinco regiões de cultura de soja em Mato Grosso, sendo elas o Médio Norte, a região Sudeste, Nordeste, região Oeste, e por fim a região Centro Sul, coletados por meio da metodologia "painel", através do Instituto Matogrossense de Economia Agropecuária - IMEA, considerando os 50 (10 produtores em cada região) agentes produtores e fornecedores de insumos com maior conhecimento do mercado presentes em cada região, pensando numa análise macro da região da produção. 
Segundo Filho et al (2009) a técnica de metodologia denominada painel é aquela onde a coleta de dados é obtida através de reuniões e encontros entre um seleto grupo de produtores rurais, técnicos, pesquisadores e comerciantes de uma região em específica, a fim de discutirem, analisarem e elegerem em conjunto as características comuns das propriedades, com o objetivo de definirem um sistema produtivo típico da região. É feito um mapeamento detalhado de todos os custos: os equipamentos (potência, consumo de combustível, coeficientes técnicos dos equipamentos (mensuração de horas para os tratos na cultura por hectare), escolha de insumos agrícolas, quantidades necessárias, preços pagos, etc). Durante essas discussões, é elaborada uma planilha de custo que representará um cenário modal dessa localidade.

Quanto à abordagem do problema, empregou-se o método quantitativo, que de acordo com Richardson (1985, p. 29), “[...] o método quantitativo representa, em princípio, a intenção de garantir a precisão dos resultados, evitar distorções de análise e interpretação, possibilitando, consequentemente, uma margem de segurança quanto às inferências".

De acordo com os objetivos, a pesquisa se caracterizou-se como exploratória. Segundo Gil (1995, p. 45), uma pesquisa exploratória “[...] tem como principal finalidade desenvolver, esclarecer e modificar conceitos e ideias, com vistas na formulação de problemas mais precisos ou hipóteses pesquisáveis para estudos posteriores".

Com base nos procedimentos técnicos utilizados, a presente pesquisa pode ser qualificado como uma pesquisa bibliográfica, documental e de levantamento. Segundo Gil (1995, p. 71), uma pesquisa bibliográfica “[...] é desenvolvida a partir de material já elaborado, constituído principalmente de livros e artigos científicos [...]"; uma pesquisa documental pois " [...] vale-se de materiais que não receberam ainda um tratamento analítico, ou que ainda podem ser reelaborados de acordo com os objetivos da pesquisa [...]”; e por fim de levantamento visto que "[...] procede-se à solicitação de informações a um grupo significativo de pessoas acerca do problema estudado para em seguida, mediante análise quantitativa, obter as conclusões correspondentes aos dados coletados”.

Em relação à análise da rentabilidade será utilizado como ferramenta o levantamento de preço de comercialização praticado tanto para a cultura de soja convencional, como para a transgênica a fim de se obter qual variedade é mais rentável. Este capítulo procura definir e esclarecer melhor estes e outros pontos da metodologia empregada neste trabalho. 


\subsection{Fonte dos dados}

A caracterização dos sistemas produtivos das variedades convencional e transgênica foi realizada a partir do levantamento de custo de produção da cultura da soja do IMEA realizada em cinco regiões distintas compreendendo o Médio Norte (cidade de Sorriso e demais municípios da região), a região Sudeste (cidade de Campo Verde e demais municípios da região, Nordeste (representada pela cidade de Canarana e demais municípios da região), região Oeste (cidade de Sapezal e demais municípios da região), e por fim a região Centro Sul (representado por Diamantino e demais municípios da região).

Os períodos foram compreendidos em seis safras, sendo elas 2008/09, 2009/10, 2010/11, 2011/12, 2012/13, 2013/14, , identificando os efeitos dos custos de produção, de acordo com o seguinte procedimento: antes da realização do painel foram identificadas as principais regiões de produção, dentro do estado. A partir disso buscou-se o contato com sindicatos de produtores, fornecedores de insumos e outros agentes técnicos, pertencentes à cadeia que pudessem fornecer informações a cerca das características regionais da cultura da soja. Em um segundo momento, foi feita uma reunião com produtores e técnicos em cada uma das regiões selecionadas. A primeira tarefa dentro desta reunião foi a definição de uma propriedade típica, ou seja, um modelo modal, que mais se repete em cada região. Definida a propriedade, inicia-se a fase de coleta de coeficientes técnicos, e dos custos de produção propriamente ditos.

\subsection{Descrição das Variáveis}

Para a análise dos custos de produção, foram considerados os gastos com o preparo do solo antes do plantio até a efetiva colheita da produção. Seguindo a mesma metodologia de Conte e Ferreira Filho (2007) que desconsiderou os gastos de transporte pós-colheita, gastos com armazenagem e os de comercialização. As variáveis utilizadas foram: sementes (S), os químicos (Q), trabalho (L), capital $(\mathrm{K})$, terra $(\mathrm{T})$, comercialização $(\mathrm{C})$, outros $(\mathrm{O})$.

Os preços utilizados para a elaboração do banco de dados foram alcançados através da pesquisa de campo desempenhada pelo Instituto Matogrossense de Economia Agropecuária (IMEA), ou pela razão entre a despesa e a quantidade empregada. Os custos estão divididos em fixos e variáveis, ponderando que os custos fixos são compostos pelos itens: manutenção periódica e depreciação (variável capital), seguro do capital fixo (variável outros) e custo da terra (variável terra). Já o custo variável tem a composição dos seguintes itens: Sementes (variável sementes), fertilizantes e defensivos (variáveis químicos), Mão de Obra (variável 
mão de obra), operações com máquinas (variável capital), assistência técnica (variável sementes), transporte da produção (variável comercialização), beneficiamento (variável comercialização), armazenagem (variável comercialização), impostos (variável comercialização), juros do financiamento (variável capital) e despesas de comercialização (variável outros).

\subsubsection{Sementes $(\mathbf{S})$}

Caracterizam aqui como custos variáveis, os gastos com aquisição de sementes para a produção e os gastos com assistência técnica. O preço de investimento das sementes $(\mathrm{R} \$ / \mathrm{Kg}$ de semente) foi levantado através da pesquisa de campo, realizado pelo IMEA. Já os custos com assistência técnica são consultoria agronômica e análise de sementes, também levantados junto ao IMEA.

\subsubsection{Químicos (Q)}

Nesta composição, utilizaram-se os gastos com defensivos agrícolas (fungicidas, inseticidas, formicidas e acaricidas) que são os produtos utilizados no combate e prevenção de doenças ou manifestações de pragas que atacam as sementes e a plantação da soja, que ocasionam redução na produção), os herbicidas que são os produtos químicos responsáveis pelo controle de desenvolvimento das ervas daninhas, já que elas concorrem com a soja por nutrientes durante seu processo de maturação, e acabam barateando seu valor econômico por serem classificadas como impurezas no produto e os fertilizantes que nutrem o solo e aumentam a produtividade. Esses índices foram encontrados através de uma média ponderada. As informações desses gastos de produtos químicos foram levantadas junto aos produtores pesquisados. (ADAPTADO DE CONTE E FERREIRA FILHO, 2007).

\subsubsection{Trabalho (L)}

Nessa variável consideraram-se os valores incorporados pelos gastos com a mão - deobra, compreendendo os funcionários fixos e os temporários (safristas). O preço da mão de obra ( $\mathrm{R} \$$ / hora) foi o resultado entre as despesas (em $\mathrm{R} \$$ ), incluindo os encargos sociais $(45,42 \%)$ sobre o salário, e o número total de horas trabalhadas. Os gastos totais com mão de obra foram obtidos diretamente da pesquisa de campo. (ADAPTADO DE CONTE E FERREIRA FILHO, 2007).

\subsubsection{Capital (K)}


Para a determinação do preço do capital foi utilizou-se a relação entre os fluxos de serviço do capital e o acervo de capital fixo (DIAS, 1982; GARCIA, 2004). No capital aplicado na produção houve ocorreram juros e depreciação (amortização). Para o avalio de depreciação foi utilizado o método linear (BUARQUE, 1984). Foi estimada em 30 anos a vida útil das instalações, com valor residual de $30 \%$. Já a vida útil e o valor residual das máquinas foram estimados em 12 mil horas e $20 \%$ do valor inicial para os tratores, em 10 mil horas e $20 \%$ do valor inicial para as colheitadeiras e 8.000 horas e $10 \%$ do valor inicial para os equipamentos, respectivamente. (GADANHA et al, 1991). (ADAPTADO DE CONTE E FERREIRA FILHO, 2007).

Para a remuneração do capital investido nos equipamentos e instalações, utilizou-se a taxa de juros de financiamentos de máquinas e implementos ofertados aos empresários rurais. Segundo Hoffmann et al. (1987), é comum calcular os juros sobre o valor médio do capital empregado na produção. Para encontrar o valor médio do bem se utiliza a média aritmética entre o valor inicial e o valor residual do bem. Os custos referentes aos empregos do capital são calculados somando-se os custos de juros e depreciação (amortização). O estoque de capital fixo é obtido multiplicando o valor inicial de máquinas, equipamentos e instalações por sua porcentagem de uso. (ADAPTADO DE CONTE E FERREIRA FILHO, 2007).

Para o cálculo da variável operação com máquinas, as estimativas de conservação de máquinas e equipamentos foram efetuadas considerando-se uma taxa de manutenção de $50 \%$ sobre o valor inicial das máquinas (tratores e colheitadeiras), de $40 \%$ para distribuidores de calcário e pulverizadores e $80 \%$ para semeadoras. Calculou-se o consumo de combustível multiplicando-se a potência das máquinas pelo coeficiente 0,12 . O valor obtido multiplicado pelo preço do combustível forneceu o preço do consumo do combustível, em $\mathrm{R} \$ /$ hora.

\subsubsection{Terra (T)}

Para o valor do arrendamento foi considerado um padrão de preço médio da terra $(\mathrm{R}$ \$ha) na região. Essa parcela de despesa foi calculada ponderando a área total plantada com soja na propriedade e o preço do arrendamento. .(ADAPTADO DE CONTE E FERREIRA FILHO, 2007).

\subsubsection{Comercialização (C)}

Os gastos com comercialização envolveram transportes, armazenagem, beneficiamento e impostos relacionados á produção. O preço dos gastos com transporte da 
produção fornecido pelo Instituto Matogrossense de Economia Agropecuária (IMEA) é decorrente do preço do frete em relação aos portos de destinos da escoação da produção: Paranaguá e Santos. Os gastos armazenagem e beneficiamento foram obtidos das empresas responsáveis pelo processamento da soja e também por meio da pesquisa de campo realizada pelo IMEA. Os gastos com impostos são aqueles incidentes sobre a comercialização da soja: Fundo de Amparo a Cultura da Soja (FACS), Fundo Estadual de Habitação e Transporte (FETHAB), Imposto sobre propriedade rural (ITR) e o Funrural.

\subsubsection{Outros (O)}

Nessa variável foram atribuídos os gastos decorrentes com seguros do capital fixo, e despesas administrativas (material de expediente, telefone, entre outras).

\section{RESULTADOS E DISCUSSÃO}

Na sequência, foram mostrados os resultados obtidos através da pesquisa painel, bem como sua análise e discussão, tendo em vista os objetivos específicos estabelecidos no presente trabalho. Após o levantamento dos custos apurados pelo IMEA, os dados foram tabulados com custos para cada variedade, a fim de se fazer uma análise comparativa. A interpretação deu-se por meios de critérios econômicos que ordenaram uma visão gerencial dos meios de produção da cultura de soja no estado.

\subsection{Análises comparativas de custos de produção da Soja Convencional e Transgênica}

Com a difusão da soja transgênica $(R R)$, e o fato dela ser resistente ao herbicida glifosato, fez com que abrissem brechas para debates sobre as vantagens e desvantagens técnicas e econômicas desse cultivo. Esse capítulo a partir de dados secundários teve por objetivo apresentar uma análise comparativa de custos de produção entre a cultura de soja convencional e da transgênica nas cinco regiões mais relevantes do estado do Mato Grosso.

Existem estudos conceituados já realizados no Brasil sobre custos de produção sobre soja. Segundo Osaki e Batalha (2007) devido à cobrança de royalties, produzir a soja transgênica não tem vantagens significativas para a região do centro-oeste. Após analisar e levar em consideração o mesmo tratamento fitossanitário observou-se que não há diferença entre os custos de produção entre as duas culturas. 
Já Bragagnolo et al (2007) constatou que pode haver variações significativas do ganho econômico entre uma e outra cultura cultivada, pois o produtor ao decidir qual variedade irá produzir deve levar em consideração a variedade que se adapta a sua região, dificuldades de controle, maquinários e condições de lavouras. Diante disso em seu estudo, foi provado que houve uma variação entre o custo total da soja transgênica e convencional de $R$ \$1,20 por saca a mais para a convencional.

Já as tabelas posteriores demonstraram os comparativos de custos de produção de soja convencional e transgênica no estado do Mato Grosso, das safras 2008 á 2013, através dos dados obtidos através da metodologia painel, junto ao IMEA.

Tabela 1: Custos de produção entre a cultura de soja convencional e transgênica em MT, na safra de 2008/09 e 2009/10 por hectare.

\begin{tabular}{lcccc|cccc|}
\hline Ano/Safra & \multicolumn{4}{|c|}{$\mathbf{2 0 0 8 / 0 9}$} & \multicolumn{4}{c|}{$\mathbf{2 0 0 9 / 1 0}$} \\
\hline Variáveis & NGM* & $\mathbf{G M} * *$ & Var $(\%)$ & Var $(\mathbf{R} \$)$ & NGM* & GM** & Var (\%) & Var $(\mathbf{R} \$)$ \\
Sementes & 104,73 & 152,42 & 45,54 & 47,69 & 119,86 & 190,54 & 58,97 & 70,68 \\
Químicos & 958,24 & 870,57 & $-9,14$ & $-87,67$ & 769,13 & 811,02 & 5,44 & 41,89 \\
Trabalho & 25,40 & 35,50 & 39,76 & 10,10 & 25,67 & 22,03 & $-14,18$ & $-3,64$ \\
Capital & 261,14 & 338,54 & 29,63 & 77,40 & 282,27 & 264,23 & $-6,40$ & $-18,04$ \\
Terra & 257,22 & 281,39 & 9,39 & 24,17 & 256,77 & 249,39 & $-2,85$ & $-7,38$ \\
Comercialização & 169,72 & 154,81 & $-8,78$ & $-14,91$ & 185,26 & 195,33 & 5,43 & 10,07 \\
Outros & 59,01 & 74,73 & 26,64 & 15,72 & 72,01 & 93,68 & 30,09 & 21,67 \\
Total & $\mathbf{1 8 3 5 , 4 6}$ & $\mathbf{1 9 0 7 , 9 6}$ & $\mathbf{3 , 9 5}$ & $\mathbf{7 2 , 5}$ & $\mathbf{1 7 1 0 , 9 7}$ & $\mathbf{1 8 2 6 , 2 2}$ & $\mathbf{6 , 7 3}$ & $\mathbf{1 1 5 , 2 5}$ \\
\hline
\end{tabular}

Fonte: IMEA; média ponderada de custos de produção de levantamentos de safras.

NGM*: Soja Convencional; GM**: Soja Transgênica.

A tabela 1 acima revelou os custos com a soja transgênica em sua maioria são superiores aos da soja convencional. A variação mais considerável nos custos foram as sementes na safra 2008/09, sendo a semente transgênica 45,54\% equivalendo ao preço de $\mathrm{R} \$$ 47,69 e de $58,97 \%$ ou $\mathrm{R} \$ 70,68$ reais em 2009/10, sendo superior ao preço da convencional nos períodos analisados, fato tal explicado pela cobrança de royalties (propriedade intelectual) pré-fixada em $2 \%$ incidente sobre as vendas finais ou do lucro líquido obtido na produção da safra, cobrada pela empresa criadora dessa tecnologia.

A variável trabalho também teve participação considerável em relação á convencional na safra 2008/09 sendo a diferença de $\mathrm{R} \$ 10,10$, assim como o capital, a terra e os outros custos também foram superiores, tabela 1. Enquanto na safra 2009/10 a variável trabalho apresentou uma queda de $\mathrm{R} \$ 3,64$ por hectare. 
Ainda na safra 2008/09 os químicos que englobam os defensivos agrícolas (fungicidas, inseticidas, formicidas e acaricidas), herbicidas (dessecantes), e fertilizantes, tiveram uma redução de $(9,14 \%)$, pelo fato de utilizarem de 1 a 2 aplicações a menos em relação a soja convencional. Outra variável que foi mais vantajosa do que na cultura convencional é os custos com comercialização cujo gasto foi de $\mathrm{R}$ \$ 14,91 a menos por hectare de soja produzida (TABELA 1).

Outra variável expressiva na safra 2009/10 na tabela 1 é a variável outros custos que foram de 30,09\% ( $\mathrm{R} \$ 21,67)$ superior para os transgênicos, sendo esses gastos, os administrativos e de seguros do capital fixo. E os custos que não expressaram valores significativos nesta mesma safra foram os químicos e os de comercialização com valores superiores, embora não chegando a $6 \%$ se comparado com a cultura convencional. Ressaltase, porém, a queda nos custos das variáveis trabalhos, capital e terra de $-14,18 \%,-6,40 \%$ e $2,85 \%$ respectivamente.

De uma safra para a outra, percebe-se que o custo de produção por hectare com a variável semente aumentou tanto para a variedade de soja convencional como para a transgênica. Em contrapartida a tabela 1 provou ainda que os custos com os químicos diminuíram com relevância para ambas.

Tabela 2: Custos de produção entre a cultura de soja convencional e transgênica em MT, na safra de 2010/11 e 2011/12, por hectare.

\begin{tabular}{lcccc|cccc|}
\hline Ano/Safra & \multicolumn{4}{|c|}{$\mathbf{2 0 1 0 / 1 1}$} & \multicolumn{4}{c|}{$\mathbf{2 0 1 1 / 1 2}$} \\
Variáveis & NGM* & $\mathbf{G M} * *$ & Var (\%) & Var (R\$) & NGM* & GM** & Var (\%) & Var (R\$) \\
Sementes & 108,37 & 157,02 & 44,89 & 48,65 & 113,61 & 123,00 & 8,27 & 9,39 \\
Químicos & 661,42 & 668,20 & 1,02 & 6,78 & 775,75 & 788,54 & 1,65 & 12,79 \\
Trabalho & 24,84 & 23,02 & $-7,33$ & $-1,82$ & 29,89 & 40,28 & 34,76 & 10,39 \\
Capital & 262,42 & 253,65 & $-3,34$ & $-8,77$ & 246,22 & 244,00 & $-0,90$ & $-2,22$ \\
Terra & 189,46 & 182,73 & $-3,55$ & $-6,73$ & 255,25 & 266,3 & 4,33 & 11,05 \\
Comercialização & 151,15 & 163,14 & 7,93 & 11,99 & 184,22 & 196,62 & 6,73 & 12,4 \\
Outros & 70,94 & 92,70 & 30,67 & 21,76 & 68,92 & 100,11 & 45,25 & 31,19 \\
Total & $\mathbf{1 4 6 8 , 6 0}$ & $\mathbf{1 5 4 0 , 4 6}$ & $\mathbf{4 , 8 9}$ & $\mathbf{7 1 , 8 6}$ & $\mathbf{1 6 7 3 , 8 6}$ & $\mathbf{1 7 5 8 , 8 5}$ & $\mathbf{5 , 1 0}$ & $\mathbf{8 4 , 9 9}$ \\
\hline
\end{tabular}

Fonte: IMEA; média ponderada de custos de produção de levantamentos de safras.

NGM*: Soja Convencional; GM**: Soja Transgênica.

A tabela 2 demonstrou que na safra 2010/11, o custo mais significativo é com as sementes que representam 44,89\% a mais para os transgênicos e os Outros custos que englobam seguros do capital fixo e despesas administrativas, representando 30,67\% superiores em relação a cultura convencional. 
Os gastos com os químicos estiveram constantes nas duas culturas nessa safra, tendo a variação de 1,02 \%. Os gastos com comercialização na soja transgênica foram superiores 7,93 \% (nessa variável estão embutidos gastos com comercialização envolvem transportes, armazenagem, beneficiamento e impostos relacionados á produção). Porém ao analisar os custos com trabalho, capital, e terra, a cultura transgênica apresentou respectivamente redução na variação nos seus custos, de -7,33\%, -3,34\% e -3,55\% (TABELA 2).

Percebeu-se também na tabela 2 que na safra de 2011/12, a variação de custos com sementes transgênicas decaiu em relação aos anos anteriores quando comparada a soja convencional, mas ainda sim apresentou nesta safra a variação 8,27 \% superior. Esse reflexo de redução é dado pela ação judicial coletiva dos sojicultores juntamente com a Federação da Agricultura e Pecuária do Mato Grosso (FAMATO), contra a cobrança de royalties sobre a soja transgênica, cuja cobrança fora suspensa via judiciário a partir do dia 08/10/2012 para o estado do Mato Grosso e dia 17/10/2013 para todo o país, conforme Rocher (2012).

A variável Outro custo foi a variação que mais gerou expressão, sendo para a cultura transgênica 45,25 \% superior á convencional, e logo após a variável trabalho, cuja representatividade foi de $34,76 \%$ também superior a soja convencional. As variáveis que não apresentaram expressivas variações, porém, ainda superiores aos custos da cultura convencional, foram: os químicos, cuja cultura transgênica obteve uma variação 1,65\% a mais, os custos com a terra cujo percentual foi de $4,33 \%$ superior e os custos de comercialização que representaram $6,73 \%$ de custo a maior nessa safra. Já a variável capital apresentou uma pequena queda na variação de custo em relação a soja convencional de 0,90 $\%$, (TABELA 2).

Tabela 3: Custos de produção entre a cultura de soja convencional e transgênica em MT na safra de 2012/13 e 2013/14, por hectare.

\begin{tabular}{lcccc|cccc|}
\hline Ano/Safra & \multicolumn{4}{c|}{$\mathbf{2 0 1 2 / 1 3}$} & \multicolumn{4}{c|}{$\mathbf{2 0 1 3 / 1 4}$} \\
\hline Variáveis & NGM* & GM** & Var (\%) & Var (R\$) & NGM* & GM** & Var (\%) & Var (R\$) \\
Sementes & 121,88 & 125,06 & 2,61 & 3,18 & 143,78 & 155,68 & 8,28 & 11,9 \\
Químicos & 859,64 & 863,59 & 0,46 & 3,95 & $1.070,67$ & $1.058,88$ & $-1,1$ & $-11,79$ \\
Trabalho & 35,52 & 48,52 & 36,6 & 13 & 65,89 & 71,07 & 7,86 & 5,18 \\
Capital & 229,01 & 239,41 & 4,54 & 10,4 & 295,39 & 288,21 & $-2,43$ & $-7,18$ \\
Terra & 297,03 & 324,83 & 9,36 & 27,8 & 400,17 & 396,8 & $-0,84$ & $-3,37$ \\
Comercialização & 203,72 & 213,22 & 4,66 & 9,5 & 250,29 & 250,20 & $-0,03$ & $-0,09$ \\
Outros & 65,97 & 91,41 & 38,53 & 25,44 & 107,84 & 110,96 & 2,89 & 3,12 \\
Total & $\mathbf{1 8 1 2 , 7 7}$ & $\mathbf{1 9 0 6 , 0 4}$ & $\mathbf{5 , 1 4}$ & $\mathbf{9 3 , 2 7}$ & $\mathbf{2 3 3 4 , 0 3}$ & $\mathbf{2 3 3 1 , 8 0}$ & $\mathbf{- 0 , 0 9}$ & $\mathbf{- 2 , 2 3}$ \\
\hline
\end{tabular}

Fonte: IMEA; média ponderada de custos de produção de levantamentos de safras. NGM*: Soja Convencional; GM**: Soja Transgênica. 
Nestes períodos vigorava a liminar coletiva movida pela FAMATO a favor da suspensão da cobrança dos royalties (ROCHER, 2012). Mesmo diante dessa ação verificou-se a partir dos levantamentos de custos de produção das safras 2012/13 e 2013/14 apresentados na tabela 3, que os valores das sementes transgênicas continuam superior ao preço de aquisição quando comparada a soja convencional, porém com variações bem abaixo as safras anteriores. Em 2012/13 a diferença em reais entre a NGM e a GM, foi de R \$ 3,18 a menos por hectare para a convencional, enquanto na safra posterior, foi de $\mathrm{R} \$ 11,90$ por hectare.

A tabela 3 demonstrou a evolução no custo da variável Outros custos, como a mais expressiva para a cultura soja transgênica na safra 2012/13, uma variação de 38,53 \% em relação a cultura convencional, seguida da variável trabalho que também teve uma variação desfavorável de 36,60 \% a mais para a cultura transgênica, assim como a variável terra com a variação de $\mathrm{R} \$ 9,50(9,36 \%)$ a mais por hectare do que a soja convencional .

As variáveis que não expressaram grandes variações nessa safra conforme a tabela 3, dentro das regiões estudadas foram os gastos com comercialização, capital, sementes e químicos, cujas variações foram 4,66 \%, 4,54\%, 2,61\% e 0,46\% respectivamente em relação a soja convencional. Percebeu-se nessa safra que todos os custos com a variedade convencional, foram menores do que os custos com a variedade transgênica.

A diferença nos preços das sementes na safra 2013/14, entre os transgênicos e convencionais foi de um total de $8,28 \%$ superior para os geneticamente modificados. Já o preço do trabalho a variação foi de 7,86 \% superior para os transgênicos. Os outros custos como despesas administrativas e seguro de capitais fixos para os geneticamente modificados também foram superiores quando analisado ao convencional, com uma variação de 2,89\%. (TABELA 3).

Destacou-se, porém na tabela 3, que nessa safra de 2013/14 a maior parte dos custos da variedade transgênicos apresentou uma queda quando comparados a variedade convencional. São eles: os químicos com uma redução de 1,10 \% ou R $\$ 11,79$ por hectare, o Capital cuja redução foi de 2,43 \% em relação ao convencional ( $\mathrm{R}$ \$ 7,08), a variável terra com redução de $0,84 \%$, expressado por uma diferença de $\mathrm{R} \$ 3,37$, e a comercialização mantendose constante o preço para as duas variedades analisadas.

Leitão et al (2010) corrobora com os resultados dos levantamentos de custos apontados acima, visto que em sua pesquisa os produtores entrevistados citaram que um dos 
fatores que elevam o custo de produção na cultura da soja transgênica é o fato que os preços da variável químico apresentaram aumento maior do que o considerado "normal", inviabilizando o aumento de áreas para plantio do cultivo da variedade GM.

Machado (2008) também confirma essa observação, já que segundo a empresa Monsanto, dois fatores são os responsáveis pelo aumento dos preços atuais dos herbicidas: o incremento do preço do petróleo, visto que ele interfere diretamente nas matérias primas que compõem o produto, variação cambial do dólar e além do aumento da demanda global do produto.

Machado (2008) ainda respalda os resultados, ao afirmar que o custo de aquisição da variável semente é superior na variedade transgênica para os produtores, pela ocorrência do impedimento de multiplicação das sementes pela lei das patentes. Na safra de 2009/10 a empresa Monsanto aumentou em $17 \%$ os royalties da soja transgênica, passando a cobrar R\$ 0,05 centavos a mais, (de $\mathrm{R} \$ 0,30$ para $\mathrm{R} \$ 0,35$ por quilo). E para aqueles agricultores que plantaram a soja GM a partir de sua própria semente, contiveram que repassar $2 \%$ do valor de sua colheita para a empresa.

Conclui-se que para a apuração dos custos é necessário levar em consideração os benefícios decorrentes do sistema de produção, pois devem ser características que apontem estabilidade em seus custos, visto que a oscilação de determinados fatores, como preço de sementes e insumos, podem inviabilizar determinadas escolhas e decisões. (SAIA, 2010).

\subsection{Análise comparativa de rentabilidade para produção da Soja Convencional e Transgênica}

Um dos resultados a serem considerados pelos produtores ao analisarem uma tecnologia de produção é a rentabilidade econômica da produção em termos operacionais, ou seja, a margem de lucro, considerando os custos operacionais de produção. Conforme Franco (2009) vale ressaltar que na atividade agrícola, o preço de venda não é definido pelos produtores rurais, mas sim pela Bolsa de Mercadorias de Chicago, a Chicago Board of Trade (CBOT), que adiciona custos de transporte até os principais portos, constituindo então o preço final de comercialização da saca de soja para cada região específica.

Diante do exposto o presente trabalho levantou através dos dados do IMEA, o preço de comercialização da saca de soja das cinco maiores regiões produtoras do estado, nas findas cinco safras, conforme demonstra a tabela abaixo, para a soja de variedade convencional. 
Tabela 4: Evolução do preço de comercialização da saca de soja convencional (60 kg) por safra e região produtora.

\begin{tabular}{ccccccc}
\hline $\begin{array}{c}\text { REGIÃO } \\
\text { CIDADE }\end{array}$ & $\begin{array}{c}\text { MÉDIO NORTE } \\
\text { SORRISO }\end{array}$ & $\begin{array}{c}\text { SUDESTE } \\
\text { CAMPO VERDE }\end{array}$ & $\begin{array}{c}\text { OESTE } \\
\text { SAPEZAL }\end{array}$ & $\begin{array}{c}\text { NORDESTE } \\
\text { CANARANA }\end{array}$ & $\begin{array}{c}\text { CENTRO SUL } \\
\text { DIAMANTINO }\end{array}$ & $\begin{array}{c}\text { MÉDIA POND. } \\
\text { REGIÕES }\end{array}$ \\
\hline ANO/SAFRA & $(\mathrm{R} \$)$ & $(\mathrm{R} \$)$ & $(\mathrm{R} \$)$ & $(\mathrm{R} \$)$ & $(\mathrm{R} \$)$ & \\
$2008 / 09$ & - & - & - & - & - & - \\
$2009 / 10$ & 38,19 & 40,59 & 37,61 & 38,12 & 38,87 & $\mathbf{3 8 , 6 8}$ \\
$2010 / 11$ & 32,35 & 34,94 & 32,83 & 32,34 & 33,37 & $\mathbf{3 3 , 1 7}$ \\
$2011 / 12$ & 37,96 & 40,44 & 38,45 & 38,08 & 38,27 & $\mathbf{3 8 , 6 4}$ \\
$2012 / 13$ & 56,27 & 59,79 & 56,89 & 56,43 & 57,54 & $\mathbf{5 7 , 3 8}$ \\
$2013 / 14$ & 49,54 & 52,55 & 50,15 & 50,42 & 49,76 & $\mathbf{5 0 , 4 8}$ \\
MÉDIA POND. & $\mathbf{4 2 , 8 6}$ & $\mathbf{4 5 , 6 6}$ & $\mathbf{4 3 , 1 9}$ & $\mathbf{4 3 , 0 8}$ & $\mathbf{4 3 , 5 6}$ & \\
\hline
\end{tabular}

Fonte: IMEA; média ponderada de preço de comercialização da saca de soja.

Os resultados apontam que a média ponderada por região (cidades), durante 5 safras permaneceram sem variações muito expressivas.Verificou-se que a cidade de Campo Verde no Sudeste do estado foi a região que obteve maior índice de preço de comercialização ao se apurar a média das ultimas safras $(\mathrm{R} \$ 45,66)$, já a cidade de Sorriso ficou com a menor média, sendo de $\mathrm{R} \$ 42,86$ por unidade de saca comercializada, alcançando uma diferença de $\mathrm{R} \$ 2,80$ reais. (TABELA 4).

A média ponderada da safra de 2009/10 no estado do Mato Grosso, na tabela4 era de $\mathrm{R} \$ 38,68$ reais por saca comercializada, em 2010/11 notou-se uma queda de $\mathrm{R} \$ 5,51$, ou seja, $14,24 \%$ em relação ao ano anterior, ficando em $\mathrm{R} \$ 33,17$. Em 2011/12 o preço reagiu novamente, fechando em $\mathrm{R} \$ 38,64$, impetrando um aumento de $16,49 \%$ ( $\mathrm{R} \$ 5,47)$. Na safra 2012/13 devido ao ótimo desempenho na produção brasileira e a dificuldades encontradas pelos americanos o preço continuou a subir ainda mais, atingindo diretamente o estado pelo fato de ser o maior produtor nacional de soja, passando de $\mathrm{R} \$ 38,64$ para $\mathrm{R} \$ 57,38$, ou seja, um aumento de $48,49 \%$ ou $\mathrm{R} \$ 18,74$ por saca. Já para a safra 2013/14 os levantamentos apontam que o preço de comercialização ficará apenas atrás da safra recorde, consolidando essas estimativas o preço de $R \$ 50,48$ reais por saca de 60 quilos, sendo assim a redução estimada é de $12,02 \%$ ou $\mathrm{R} \$ 6,90$.

Segundo Pasqua (2013, p.10) as projeções confirmam os resultados:

Após se consolidar com maiores área de produção em 2012/13, o cenário pouco se alterou para a soja nas lavouras brasileiras. As perspectivas são amplamente favoráveis e encaminham novos patamares nunca alcançados, apesar de os preços médios de 2013 estarem entre 6\% e 13\% inferiores a 2012, porém são os segundos maiores da história e amplamente remuneradores aos produtores. 
A safra 2012/13 foi a que apresentou a variação mais relevante em relação as outras safras. (TABELA 4). Tal acontecimento se deu pelo fato de ter sido a maior safra da história brasileira, superando 82 milhões de toneladas, e assim pela primeira vez, o Brasil ameaçou a liderança do então líder do ranking do mercado, os Estados Unidos da América (EUA). A comercialização ocorreu de forma gradual, porém com os preços sempre acima das médias históricas, reflexo do aperto na oferta mundial do produto (PASQUA, 2013).

\subsection{Análises comparativas de produtividade e lucratividade bruta para produção da Soja Convencional e Transgênica}

Sabe-se que para que haja o aumento da produtividade das culturas agrícolas, há um conjunto de fatores que se atrelam para a obtenção de tais resultados: equipamentos de alta tecnologia, mão de obra qualificada e especializada, adequação no manejo do solo, desenvolvimento de novas sementes, redução de custos entre outras variáveis.

No caso da variedade transgênica, ela foi introduzida no mercado com o intuito de reduzir os custos, em relação ao método da cultura convencional, e com promessa de produtividade também superior (MENEGATTI e BARROS, 2007). Porém estudos realizados no país têm apresentado divergências nos resultados por diversos motivos: a falta de variedades adaptadas, alto custos das sementes (devido aos royalties), aumento nos preços dos defensivos, etc.

Em seu trabalho de pesquisa Leitão (2009) apontou por meio de entrevista com os agentes multiplicadores de sementes (empresas produtoras) que eles acreditam que não haja diferença de produtividade entre a semente de soja transgênica e convencional. Em contrapartida há quem afirma que o grande trunfo da variedade RR, é a questão de maior produtividade (ROSA, 2008; ROESSING E LAZZAROTO, 2005), Rosa (2008) ainda prova que existem alguns casos no Paraná em que a produtividade se iguala e em algumas propriedades a produção foram superiores ao da soja convencional. Já Ribeiro (2009) apontou que na região do Rio Verde- GO, alguns produtores diminuíram as áreas de plantação transgênica, dentre outros motivos por causa da redução na produtividade e a diferenciação no preço de comercialização.

Diante da problemática encontrada pela dispersão de opiniões e falta de dados disponíveis no site do IMEA sobre a produtividade e preço de venda da soja GMO, considerou-se a produtividade igualitária tanto para a variedade convencional como a para a transgênica numa área de 1 hectare , assim como também o preço praticado no estado por saca 
de soja de $60 \mathrm{~kg}$, conforme levantamento apresentado na Tabela 4. A demonstração do cenário explicita a rentabilidade gerada aos produtores levando em consideração a receita bruta menos o custo de produção auferido de cada variedade (por hectare), apontando assim o lucro bruto de cada safra e variedade a fim de sanar o objetivo específico proposto, apontando qual variedade obtém maior rentabilidade.

Tabela 5: Demonstração de produtividade, custo de produção, preço de comercialização, receita bruta e lucro bruto das safras 2009/10 a 2013/14 para a variedade de soja convencional.

\begin{tabular}{cccccc}
\hline \multicolumn{5}{c}{ SOJA CONVENCIONAL } \\
\hline SAFRA & PROD. & CUSTO & PREÇO & RECEITA & LUCRO \\
& SC & $(\mathbf{R} \$)$ & $(\mathbf{R} \$ \mathbf{S C})$ & $(\mathbf{R} \mathbf{)}$ & $(\mathbf{R} \mathbf{)}$ \\
$\mathbf{2 0 0 8}$ & 50 & $1.835,49$ & & & \\
$\mathbf{2 0 0 9}$ & 50 & $1.710,97$ & 38,67 & 1933,50 & $\mathbf{R} \mathbf{2 2 2 , 5 3}$ \\
$\mathbf{2 0 1 0}$ & 50 & $1.468,60$ & 33,16 & 1658,00 & $\mathbf{R} \mathbf{1 8 9 , 4 0}$ \\
$\mathbf{2 0 1 1}$ & 50 & $1.673,85$ & 38,64 & 1932,00 & $\mathbf{R} \mathbf{2 5 8 , 1 5}$ \\
$\mathbf{2 0 1 2}$ & 50 & $1.812,77$ & 57,38 & 2869,00 & $\mathbf{R} \mathbf{1 . 0 5 6 , 2 3}$ \\
$\mathbf{2 0 1 3}$ & 50 & $2.334,03$ & 50,48 & 2524,00 & $\mathbf{R} \mathbf{1 8 9 , 9 7}$ \\
\hline
\end{tabular}

Fonte: IMEA; média ponderada de custos de produção, e de preço de comercialização por saca de soja de safras.

Os dados da tabela 5 acima, da variedade de soja convencional, revelam que a safra 2013/14 é a safra com o custo mais elevado (R $\$ 2.334,03$ ) em seguida a safra 2012/13 com $\mathrm{R} \$ 1.812,77$, logo a safra de 2008/09, 2009/10, 2011/12 e 2010/11 respectivamente.

Quanto aos valores praticados na comercialização, a safra de 2012/13 foi o maior já alcançado com $\mathrm{R} \$ 57,38$ a saca e a expectativa com o segundo melhor preço ficou com a safra de 2013/14 com $R$ \$ 50,48 apresentando uma variação negativa de $R$ \$ 6,90 (-12,02\%). Ao considerar a produção de 50 sacas de soja por hectare e multiplicando pelo valor de comercialização, aufere-se a receita bruta, cuja maior margem também ficou com a safra 2012/13, seguida da safra 2013/14 com $\mathrm{R} \$ 2.869,00$ e $\mathrm{R} \$ 2.524,00$ respectivamente. Nota-se também que conseqüentemente o maior lucro bruto também foi o da safra 2012/13 com R\$ 1.056,23, lembrando que esta safra obteve produção recorde da história brasileira, logo a safra de 2011/12 com $\mathrm{R} \$ 258,15$,safra 2009/10 com lucro bruto de $\mathrm{R} \$ 222,53$, safra 2013/14 com $\mathrm{R} \$ 189,40$ e safra 2010/11 com a menor lucratividade $\mathrm{R} \$ 189,97$. E a diferença entre o maior lucro bruto em relação ao menor foi um percentual de 82, 07\% ou R\$ 866,83 (safra 2012/13 em relação a safra 2010/11).(TABELA 5).

Tabela 6: Demonstração de produtividade, custo de produção, preço de comercialização, receita bruta e lucro bruto das safras 2009/10 a 2013/14 para a variedade de soja transgênica.

SOJA TRANSGÊNICA 


\begin{tabular}{cccccc} 
SAFRA & $\begin{array}{c}\text { PROD. } \\
\text { SC }\end{array}$ & $\begin{array}{c}\text { CUSTO } \\
(\mathbf{R} \$)\end{array}$ & $\begin{array}{c}\text { PREÇO } \\
(\mathbf{R} \$ \mathbf{S C})\end{array}$ & $\begin{array}{c}\text { RECEITA } \\
(\mathbf{R} \$)\end{array}$ & $\begin{array}{c}\text { LUCRO } \\
(\mathbf{R} \$)\end{array}$ \\
$\mathbf{2 0 0 8}$ & 50 & $1.907,36$ & & & \\
$\mathbf{2 0 0 9}$ & 50 & $1.826,22$ & 38,67 & 1933,50 & $\mathbf{R} \mathbf{1 0 7 , 2 8}$ \\
$\mathbf{2 0 1 0}$ & 50 & $1.540,46$ & 33,16 & 1658,00 & $\mathbf{R} \mathbf{1 1 7 , 5 4}$ \\
$\mathbf{2 0 1 1}$ & 50 & $1.758,85$ & 38,64 & 1932,00 & $\mathbf{R} \mathbf{1 7 3 , 1 5}$ \\
$\mathbf{2 0 1 2}$ & 50 & $1.906,04$ & 57,38 & 2869,00 & $\mathbf{R} \mathbf{9 6 2 , 9 6}$ \\
$\mathbf{2 0 1 3}$ & 50 & $2.331,80$ & 50,48 & 2524,00 & $\mathbf{R} \mathbf{1 9 2 , 2 0}$ \\
\hline
\end{tabular}

Fonte: IMEA; média ponderada de custos de produção, e de preço de comercialização por saca de soja de safras.

Já com variedade de soja transgênica, a tabela 6 apontou também que a safra 2013/14 é a safra com o custo mais elevado (R\$ 2.331,80) em seguida a safra 2012/13 com R\$ 1906,04, logo a safra de 2008/09, 2009/10, 2011/12 e 2010/11 respectivamente, assim como na variedade convencional.

Quanto aos valores praticados na comercialização aqui também se utilizou da mesma média ponderada levantada através de dados divulgados pelo IMEA sobre os valores praticados no mercado para a comercialização da soja convencional, a tabela 6 demonstrou então que a safra de 2012/13 foi o maior já alcançado com $\mathrm{R} \$ 57,38$ a saca e a expectativa com o segundo melhor preço ficou com a safra de 2013/14 com $\mathrm{R} \$ 50,48$ apresentando uma variação negativa de $\mathrm{R} \$ 6,90$ (-12,02\%). Ao considerar a produção de 50 sacas de soja por hectare e multiplicando pelo valor de comercialização, aufere-se a receita bruta, cuja maior margem também ficou com a safra 2012/13, seguida da safra 2013/14 com R \$ 2.869,00 e R\$ 2.524,00 respectivamente. Nota-se também que conseqüentemente o maior lucro bruto também foi o da safra 2012/13 com $\mathrm{R} \$ 962,96$, logo a safra de 2013/14 com R\$ 192,20, safra 2011/12 com lucro bruto de $\mathrm{R} \$ 173,15$, safra 2010/11 com $\mathrm{R} \$ 117,54$ e safra 2009/10 com a menor lucratividade, $\mathrm{R} \$ 107,28$. (TABELA 6).

Tabela 7: Variação de lucro bruto entre as variedades de soja convencional e transgênica.

SOJA CONVENC.

\begin{tabular}{cccc}
\hline SAFRA & LUCRO BRUTO & LUCRO BRUTO & VARIAÇÃO \\
\hline 2008 & $(\mathbf{R} \$)$ & $(\mathbf{R} \$)$ & $(\mathbf{\%})$ \\
2009 & $\mathrm{R} \$ 222,53$ & $\mathrm{R} \$ 107,28$ & $\mathbf{1 0 7 , 4 7 \%}$ \\
2010 & $\mathrm{R} \$ 189,40$ & $\mathrm{R} \$ 117,54$ & $\mathbf{6 1 , 1 4 \%}$ \\
2011 & $\mathrm{R} \$ 258,15$ & $\mathrm{R} \$ 173,15$ & $\mathbf{4 9 , 1 7 \%}$ \\
2012 & $\mathrm{R} \$ 1.056,23$ & $\mathrm{R} \$ 962,96$ & $\mathbf{9 , 8 6 \%}$
\end{tabular}


2013

Fonte: Resultados da pesquisa

A tabela 7 demonstra a variação ocorrida no lucro bruto da soja convencional em relação à soja transgênica, ao decorrer das safras. Nota-se que desde a safra 2009/10 até a safra 2012/13 a variação sempre era positiva para a variedade convencional, porém decrescente ano a ano, e que apenas na safra 2013/14 apontou resultado de lucro bruto superior para a variedade transgênica. Essa variação aconteceu pelo fato de que os custos com químicos, capital, terra e comercialização na safra 2013/14 foram inferior ao dá soja NGM, conforme as tabelas 1 e 2 .

Percebe-se também na tabela 7 que a maior variação de lucro, (2009/10) com o índice de $107,47 \%$, uma diferença de $\mathrm{R} \$ 115,25$ a mais na rentabilidade da soja convencional. Em seguida a safra 2010/11 com variação de 61,14 \% ou $\mathrm{R} \$ 71,86$, logo após a safra de 2011/12 cuja rentabilidade foi de $\mathrm{R} \$ 85,00$, representando $49,17 \%$ de lucro bruto. Seguindo ainda essa rentabilidade superior para a variedade convencional, a safra de 2012/13 obteve saldo positivo de $9,86 \%$ (R $\$ 93,27)$. E a safra 2013/14 foi a única com variação negativa para a variedade convencional, apresentando uma queda na rentabilidade de $\mathrm{R} \$ 2,23$ ou $(1,16 \%)$.

Tal comportamento da decrescente rentabilidade para a variedade convencional ao longo dos anos deu-se pelo fato de que no início da análise a aceitação do mercado estava restrita á variedade transgênica por diversos fatores, como dúvidas quanto á adaptação, produtividade, mercado consumidor e preço. Aos poucos esses paradigmas foram se estreitando e os produtores ficaram confiantes e optou-se por abrir novas fronteiras para o aumento da produção (aumento de área de plantação), e consequentemente a soja transgênica foi ganhando maior destaque no mercado, tanto interno como externo, expandindo e acompanhando essa alavancagem da questão preço nessa nova tendência.

\section{CONSIDERAÇÕES FINAIS}

O objetivo proposto da pesquisa foi determinar comparativamente os custos de produção e rentabilidade para as culturas de soja convencional e transgênica das findas seis safras (2008/09 á 2013/14), e os mesmos foram alcançados através do levantamento de dados com metodologia via painel, disponíveis no IMEA. 
Constatou-se que os gastos com químicos e sementes foram as variáveis que mais oneraram os custos na variedade transgênica em todas as safras. Tal explicação dá-se pelo fato da cultura GM estar utilizando mais de uma aplicação de herbicida no cultivo, outro motivo é o fato do aumento dos preços atuais dos herbicidas: o incremento do preço do petróleo e variação cambial do dólar. Já no caso das sementes o impetrante dá-se pela cobrança de royalties.

Como considerações finais foi possível constatar que mesmo diante da proposta original destacada pela empresa patenteadora da tecnologia da variedade de soja transgênica em proporcionar menores custos, facilidade de manejo e aumento de produtividade os desígnios não foram alcançados. A análise dos custos e a rentabilidade nas cinco regiões produtoras definidas do estado provaram que a opção pela variedade de soja convencional ainda é mais vantajosa, pois apresenta menores oscilações nos custos quando comparadas a variedade transgênica e consequentemente um lucro bruto superior ao da soja transgênica para os produtores rurais.

A limitação encontrada na pesquisa deu-se pela falta de informações disponíveis quanto ao preço de comercialização e a produtividade nos referidos períodos para a variedade de soja transgênica, impeliu-se então a construção de um cenário semelhante ao da variedade de soja convencional. Para a produtividade fixou-se a quantidade de 50 (cinquenta) sacas por hectares (assim também como foi utilizada para a variedade convencional), e para a rentabilidade utilizou-se novamente a média de preços das regiões, levantadas na variedade convencional, como o preço de comercialização também para a variedade transgênica. Já na apuração do lucro bruto, utilizou-se para ambas a receita bruta (quantidade produzida x preço de venda) e desse resultado diminuiu-se os custos levantados das respectivas variedades.

E como sugestões para trabalhos futuros é possível analisar safras posteriores para comparar os comportamentos de custos de produção e preço de comercialização, desenvolver a pesquisa em outras regiões no Mato Grosso e ainda utilizar a pesquisa e o método em outros produtos como o milho e o algodão.

\section{REFERÊNCIAS}

ANDRADE, M.G.F. DE; MORAIS, M.I. DE; MUNHÃO, E.E; PIMENTA, P.R. Controle de custos na agricultura: um estudo sobre a rentabilidade na cultura da soja. Custos e agronegócio online, Recife, volume 8, número 3, p. 1-173, Julho/Setembro. 2012. 
APROSOJA - Associação dos Produtores de Soja do Estado de Mato Grosso, 2013.

Disponível em < http://www.aprosoja.com.br/sobre-a-soja/Paginas/Historia-da-Soja.aspx>. Acesso em: 12.03.2013.

APROSOJA, Associação dos Produtores de Soja do Estado de Mato Grosso. Levantamento de safra - MT. Disponível em

$<$ http://www.aprosoja.com.br/novosite/estatisticav.php?cate=1>. Acesso em: 25.10. 2010.

BUARQUE, C. Avaliação econômica de projetos. Rio de Janeiro: Campus, 1984. 266 p.

BRAGAGNOLO, C.; MAFIOLETTI, R.L.; SBISSIA, G.F.; TURRA, F.E. Análise dos custos de soja no Paraná : Convencional x Transgênica (RR). Anais ... XLIII Congresso Brasileiro de economia e Sociologia Rural. SOBER. Londrina-PR: 2007. CD ROM.

BRUNI, A.L.; FAMÁ, R. Gestão de Custos e Formação de Preços: com aplicações na calculadora HP 12C e Excel. 3ª Edição. São Paulo: Atlas, 2004.

CELESTINO, João Garibaldi Almeida Viana Vicente; SILVEIRA, Pires. Análise econômica da ovinocultura: estudo de caso na Metade Sul do Rio Grande do Sul, Brasil. Ciência Rural, v. 39, n. 4, p. 1187-1192, 2009.

CONTE, L; FERREIRA FILHO, J. B. S. Substituição de fatores produtivos na produção de soja no Brasil. Revista de Economia e Sociologia Rural, v. 45, p. 475, 2007.

CORONADO, O. Contabilidade Gerencial Básica. São Paulo: Saraiva, 2006.

COSTA, A. J. D. ALMEIDA, M. J. M. O Complexo Agroindustrial Paranaense: Soja Transgênica versus Soja Convencional, 2007. Disponível em:

http://www.ecopar.ufpr.br/artigos/a4_031.pdf. Acesso em 05 de maio de 2013.

CREPALDI, S. A. Contabilidade Gerencial: Teoria e Prática. 3 ed. São Paulo: Atlas, 2006.

Contabilidade Rural: uma abordagem decisorial. 6 ed. São Paulo: Atlas, 2011.

DIAS, R.S. Elasticidade de substituição e de demanda de fatores na agricultura

brasileira. 1982. 58 p. Dissertação (Mestrado em Economia Rural) - Universidade Federal de Viçosa, Viçosa, 1982.

ESPERANCINI, M.S.T; FURLANETO, F.P.B.; RECO, P.C.; OJIMA, A.L.R.O.; YASUDA, G.M. Retorno e risco econômico no cultivo de soja convencional e transgênica na região paulista do médio Paranapanema, safra 2006/07. Anais...XLIII Congresso Brasileiro de economia e Sociologia Rural.SOBER. Rio Branco-AC :2008- CD ROM.

EYERKAUFER, Marino Luiz; COSTA Adilson; FARIA, Ana Cristina de. Métodos de custeio por absorção e variável na ovinocultura de corte: estudo de caso em uma cabanha. Organizações Rurais \& Agroindustriais, Lavras, v. 9, n. 2, p. 202-215, 2007.

FILHO,J.B.S.F; ALVES, L.R.A; VILLAR, P.M.V. Estudo de competitividade da produção de algodão entre Brasil e Estados Unidos- safra 2003/04. Revista de Economia Sociologia e Rural, vol 47, nª 01Jan/Mar. 2009. 
FRANCO, C.; EIDT, K.M; ANUNCIATO, K.M.; TORRES, A.L.; FERRERIRA, M.G.A. Soja convencional versus soja transgênica: Análise comparativa de custos de produção e rentabilidade na fazenda Missioneira, Campo Novo dos Parecis- MT. Anais... XLIII Congresso Brasileiro de Economia e Sociologia Rural.SOBER, Campo Grande-MS: 2010.

FURLANETO,F.P.B.; RECO, P.C.; KANTHACK, R.A.D; ESPERANCINI, M.S.T; OJIMA, A.L.R.O. Soja transgênica versus convencional: estimativa de custos operacionais de produção na região do médio Paranapanema, estado de São Paulo. 2008. Disponível em http://ideas.repec.org/p/ags/sbrfsr/109764.html. Acesso em 15/08/2013.

GADANHA, D.C.; MOLIN, J.P.; COELHO, J.L.D.; YAHN, C.H.; TOMIMORI, S.M.A.W. Máquinas e implementos agrícolas do Brasil. São Paulo: IPT, 1991. 468 p.

GARCIA, L.A.F. Economias de escala na produção de frangos de cortes no Brasil. 2004. 114 p. Tese (Doutorado em Economia Aplicada). - Escola Superior de Agricultura "Luiz de Queiroz", Universidade de São Paulo, Piracicaba, 2004.

GIL, A. C. Métodos e técnicas de pesquisa social. São Paulo: Atlas, 1995.

GREENPEACE. Soja transgênica no Brasil, contaminação e royalties. Campanha de engenharia genética. 2004. Disponível em

>http://www.greenpeace.org.br/transgenicos/pdf/contaminacao.pdf . Acesso em Maio de 2013.

GUERREIRO, Reinaldo. Estruturação de sistemas de custos para a gestão da rentabilidade. São Paulo: Atlas, 2011.

HOFFMANN, R.; ENGLER, J.J. de C.; SERRANO, O. Administração da empresa agrícola. 2.ed. São Paulo: Pioneira, 1987. 325 p.

IMEA. Instituto matogrossense de pesquisa agropecuária. Custos de produção de soja para Mato Grosso. Disponível em: <http://www.imea.com.br>. Acesso em 01.08.2013.

LEITÃO, F. O. Análise da coexistência da soja transgênica e convencional no Mato Grosso: rumo a novas formas de governança. 2009. $151 \mathrm{f}$. Dissertação (Mestrado Interdisciplinar) - Programa de Pós Graduação em Agronegócios,Universidade de Brasília, Brasília. Disponível em http://repositorio.unb.br/bitstream/10482/4509/1/2009_FabricioOliveiraLeitao.pdf. Acesso em 10/06/2013.

LEITÃO, F. O.; MEDEIROS, J.X.; THOMÉ, K.M.; CARVALHO,J.M.; BRISOLA, M.V. Cultivo de soja transgênica no estado do Mato Grosso: Fatores propulsores e limitativos. 2010. Disponível em http://ftp.sp.gov.br/ftpiea/publicacoes/rea/2010/rea1-5-2010.pdf. Acesso em $15 / 08 / 2013$.

MACHADO, P. Transgênico da prejuízo para produção na safra 2008/09., AS-PTAAssociação Familiar e Agroecologia.Cuiabá, 09/09/2008. Disponível em http://aspta.org.br/campanha/soja-transgenica-perde-espaco-no-mato-grosso/. Acesso em $13 / 10 / 2013$. 
MALAVAZI, DE SOUZA, A.; FUGITA, D. E; ROSA, P.M. Custeio variável como um instrumento de gestão para as empresas rurais. Anais 2006 da Semana de Ciências Contábeis da Universidade Estadual de Maringá (UEM), Maringá, 2006.

MARION, J. C.Contabilidade Rural. 6. ed. São Paulo: Editora Atlas, 2000.

MARTINS, Eliseu. Contabilidade de Custos. Inclui o ABC. 8. ed. São Paulo: Editora Atlas, 2001.

MEDEIROS, Lessandra. Comparativo de Custos de Produção entre Soja Convencional e a Soja Transgênica na Safra 2002/2003 - Rio Grande do Sul. Contexto: Revista do Núcleo de Estudos e Pesquisas em Contabilidade da UFRGS. Rio Grande do Sul, ed. 5, $2^{\circ}$ semestre de 2003.

MEGLIORINI, Evandir. Custos: análise e gestão. 2 ed. São Paulo: Pearson Prentice Hall, 2011.

MENEGATTI, A. L. A. Custo de produção para soja convencional e transgênica a luz das metodologias utilizadas pelos órgãos públicos no Brasil e nos Estados Unidos: um estudo para o estado do Mato Grosso do Sul. Dissertação submetida à Escola Superior de Agricultura Luiz de Queiroz (ESALQ) para a obtenção do título de mestre em Ciências. Área de concentração: Economia Aplicada. Piracicaba, agosto de 2006. Disponível em:

http://www.teses.usp.br/teses/disponiveis/11/11132/tde-03102006-171619/ Acesso em: 01 maio 2013.

MENEGATTI, A. L.; BARROS, A.L.M. Análise comparativa dos custos de produção entre soja transgênico e convencional: um estudo de caso para o estado do Mato Grosso do Sul. Revista de Economia Rural. Vol. 45. P.163-183. Rio de Janeiro, 2007.

NASCIMENTO, J. M. Custos: Planejamento, Controle e Gestão na Economia Globalizada. 2. ed. São Paulo: Atlas, 2001.

OSAKI, M; BATALHA, M.O. Mudanças do sistema de produção da soja com o OGM. Anais... XLIII Congresso Brasileiro de economia e Sociologia Rural.SOBER. Londrina-PR: 2007.

PASQUA, Dylan Della,2013. Recorde á vista. Mais um. Revista A Granja. 28 edição, editora Centaurus, ano 2013/2014, pag. 10-18.

RIBEIRO, Osni Moura. Contabilidade de custos. 1 ed. São Paulo: Saraiva, 2009.

RICHARDSON, R. J. Pesquisa social: métodos e técnicas. São Paulo: Atlas, 1985.

ROSA, A. TransgênicaX Convencional. Gazeta do Povo- Curitiba. Ed. Caminho do Campo, 01 e 03. Publicado no Jornal Gazeta do Povo- Curitiba. 2008. Disponível em < htpp:// www..merweb.com.br/clinetes/anbionoticias/geral2.asp?cod5005. Acesso em 25 de Julho de 2013.

ROCHER, José. Monsanto suspende royalties da soja RR em todo o Brasil. Gazeta do PovoCuritiba. 2012. Disponível em http://agro.gazetadopovo.com.br/arquivo/monsanto-suspenderoyalties-da-soja-rr-em-todo-o-brasil/. Acesso em 08/10/2013. 
ROESSING, A.C.; LAZAROTTO, J.J. Soja transgênica no Brasil: Situação atual e prespectivas par aos próximos anos. Anais... XLIII Congresso Brasileiro de economia e Sociologia Rural.SOBER. Ribeirão Preto: 2005. CD-ROM

SAIA, V.P.; PIGATTO, G.P.; SANTINI, G.A. Custos comparativos da produção de soja transgênica e convencional para o estado de São Paulo. Anais... XLIII Congresso Brasileiro de Economia e Sociologia Rural.SOBER, Campo Grande-MS: 2010. 